\title{
Análise de manifestações patológicas provenientes da umidade através de estudo de caso em Boa Vista do Buricá/RS
}

D. A, Hanauer (1); A. P, Maran (2)*; M. F. F, Menna Barreto (3); M. M, Copetti(4); J. E, Wille (5)

*Autor de Contacto: anapaulamaran@gmail.com

(1) Curso de Engenharia Civil, Universidade Regional do Noroeste do Estado do Rio Grande do Sul (UNIJUI), Santa Rosa, Brasil.

(2) Curso de Arquitetura e Urbanismo, Universidade Federal de Santa Maria (UFSM), Cachoeira do Sul, Brasil.

(3) Programa de Pós-Graduação em Engenharia Civil (PPGCI), Universidade Federal do Rio Grande do Sul, Porto Alegre, Brasil.

(4) Curso de Arquitetura e Urbanismo, Universidade Federal de Santa Maria (UFSM), Cachoeira do Sul, Brasil.

(5) Curso de Arquitetura e Urbanismo, Universidade Regional do Alto Uruguai e das Missões (URI), Santo Ângelo Brasil.

\section{Resumo}

Apesar do conhecimento da importância da impermeabilização nas edificações, esta etapa ainda é muito negligenciada durante o processo de especificação e execução das obras. A consequência desta realidade resulta no aparecimento de manifestações patológicas provenientes da umidade. Este trabalho tem por finalidade analisar as causas e problemas que estão relacionados à falta de impermeabilização em habitações de interesse social na cidade de Boa Vista do Buricá/RS. Com análise in loco, foram obtidos os dados através de entrevistas e levantamento fotográfico, podendo assim, realizar o diagnóstico, as causas e efeitos das manifestações, além da indicação de recuperação. As quatorze residências analisadas apresentaram intercorrência em relação à umidade, e na maioria dos casos, foi constatado que os problemas surgiram por execução não controlada de impermeabilização.

Palavras chaves: Impermeabilização; Manifestações Patológicas; Umidade; Habitação de Interesse Social.

\section{Abstract}


Despite the knowledge of the importance of waterproofing in buildings, this step is still very neglected during the specification and execution process of the works. The consequence of this reality results in the appearance of pathological manifestations arising from humidity. This work aims to analyze the causes and problems that are related to the lack of waterproofing in social housing in the city of Boa Vista do Buricá / RS. With on-site analysis, data were obtained through interviews and photographic survey, thus being able to make the diagnosis, the causes, and effects of the manifestations, in addition to the indication of recovery. The fourteen households analyzed presented complications in relation to humidity, and in most cases, it was found that the problems arose due to uncontrolled waterproofing.

Keywords: Waterproofing; Pathological Manifestations; Humidity; Social Interest Housing.

\section{Resumen}

A pesar del conocimiento de la importancia de la impermeabilización en edificaciones, este paso sigue estando muy descuidado durante el proceso de especificación y ejecución de las obras. La consecuencia de esta realidad resulta en la aparición de manifestaciones patológicas derivadas de la humedad. Este trabajo tiene como objetivo analizar las causas y problemas que se relacionan con la falta de impermeabilización en viviendas sociales de la ciudad de Boa Vista do Buricá / RS. Con el análisis in situ, se obtuvieron datos a través de entrevistas y levantamiento fotográfico, pudiendo así realizar el diagnóstico, las causas y efectos de las manifestaciones, además de la indicación de recuperación. Los catorce hogares analizados presentaron complicaciones en relación a la humedad, y en la mayoría de los casos, se encontró que los problemas surgieron por impermeabilizaciones incontroladas.

Palabra clave: Impermeabilización; Manifestaciones patológicas; Humedad; Vivienda de Interés Social.

\section{INTRODUÇÃO}

Souza (2008) diz que a degradação prematura das edificações ou suas partes, e a consequente redução de desempenho exigido (ABNT NBR 15575, 2021) é um problema frequente nas construções. Esta deterioração ocorre devido, sobretudo, ao envelhecimento precoce, o qual geralmente é desencadeado pela baixa qualidade dos materiais de construção empregados, por erros de especificação em projeto, falhas no controle da execução e falta de manutenção.

Perante esta realidade, o estudo de patologias das edificações se faz necessário, como forma de recuperação e estudo de comportamento, como forma de evitar e prevenir futuras manifestações (WALDHELM, 2012). Conforme Suplicy (2012), a engenharia utiliza o termo patologia para estudar nas construções as manifestações, suas origens, seus mecanismos de ocorrência das falhas e seus defeitos que alteram o equilíbrio pré-existente.

Para Brito (2011), apesar da indústria da construção estar sempre evoluindo no campo das técnicas e dos materiais de construção e se adequando aos programas de qualidade, percebe-se que as patologias ainda vêm sendo um grande desafio para os profissionais da construção civil. Souza (2008) estima que até $60 \%$ das manifestações patológicas presentes em edificações em uso e operação são causadas por umidade, podendo gerar prejuízos econômicos, estéticos, estruturais, funcionais, além de representar risco à saúde e segurança dos usuários. 
Grande parte dos componentes das edificações não possui resistência ao intemperismo, sofrendo ação conjunta com água, oxigênio, vapores e agentes agressivos presentes no ambiente (CASTRO, 2014). Desta forma, a consideração de impermeabilização através de especificação de sistemas compatíveis com a área de utilização auxilia na garantia do desempenho da construção.

A NBR 9575 (ABNT, 2010) define a impermeabilização como um "conjunto de operações e técnicas construtivas (serviços), composto por uma ou mais camadas, que tem por finalidade proteger as construções contra a ação deletérias de fluídos, vapores e da umidade".

No Brasil, diversos produtos impermeabilizantes, com qualidade, desempenho e método de aplicação variáveis são encontrados no mercado (RIGHI, 2009). É importante salientar que o sistema a ser empregado precisa ser compatível com a localização da edificação e o tipo de ocorrência de umidade.

Para Yazigi (2009), a impermeabilização deve ser seguida conforme solicitada nos documentos técnicos da obra, e caso sua execução seja feita incorretamente pode acarretar patologias na edificação, como a presença em excesso de umidade. Magalhães et al. (2019) afirmam que a etapa executiva normalmente é bastante negligenciada por parte dos construtores, responsáveis pela garantia da estanqueidade da edificação.

De acordo com Pieper (1992), a umidade nas construções é frequente e de difícil correção. Para Ripper e Souza (1998), os custos, assim como as dificuldades técnicas para a recuperação das falhas, que se originam na fase inicial da obra, aumentam conforme a estrutura vai sendo construída. Logo, a falha originada na etapa de concepção da obra irá gerar mais custos após a mesma estar concluída, quando comparada a medidas adotadas como forma de preveni-la, como a execução correta de sistemas de impermeabilização.

Verçoza (1991) reitera que a umidade não é apenas uma causa de patologias, como também é um meio necessário para outras patologias ocorram, sendo fator essencial para o aparecimento de eflorescências, ferrugens, mofo, bolores, perda de pintura e revestimentos, por exemplo.

Dentro deste contexto, este trabalho buscou verificar e avaliar as manifestações patológicas ocasionadas pela umidade através de levantamento em campo após a execução e entrega de habitações térreas de interesse social na cidade de Boa Vista do Buricá/RS, indicando os locais de maior incidência e apresentando soluções técnicas apropriadas para o correto tratamento.

\section{PROCEDIMENTO}

Com o objetivo de identificar e analisar as manifestações patológicas existentes nas habitações escolhidas para o estudo in loco, determinando os locais onde as mesmas ocorrem e a fim de apresentar soluções técnicas adequadas para sua recuperação, foram coletados os dados e categorizadas as manifestações nas diferentes residências.

Cada dado coletado foi filtrado e organizado por categoria, sendo assim, separado devido sua manifestação patológica ocorrente em cada edificação, assim como, em cada cômodo da edificação.

Após esta organização fez-se então a análise de cada manifestação patológica, seguido de uma sugestão de correção direcionada ao problema correspondente.

As obras escolhidas para o desenvolvimento de estudo de caso são classificadas como habitação de interesse social do município de Boa Vista do Buricá/RS. Estas residências totalizam 14 edificações idênticas em seu projeto original (Figura 1) com $30 \mathrm{~m}^{2}$ e algumas sofreram alterações posteriores à entrega aos moradores (Figura 2). 


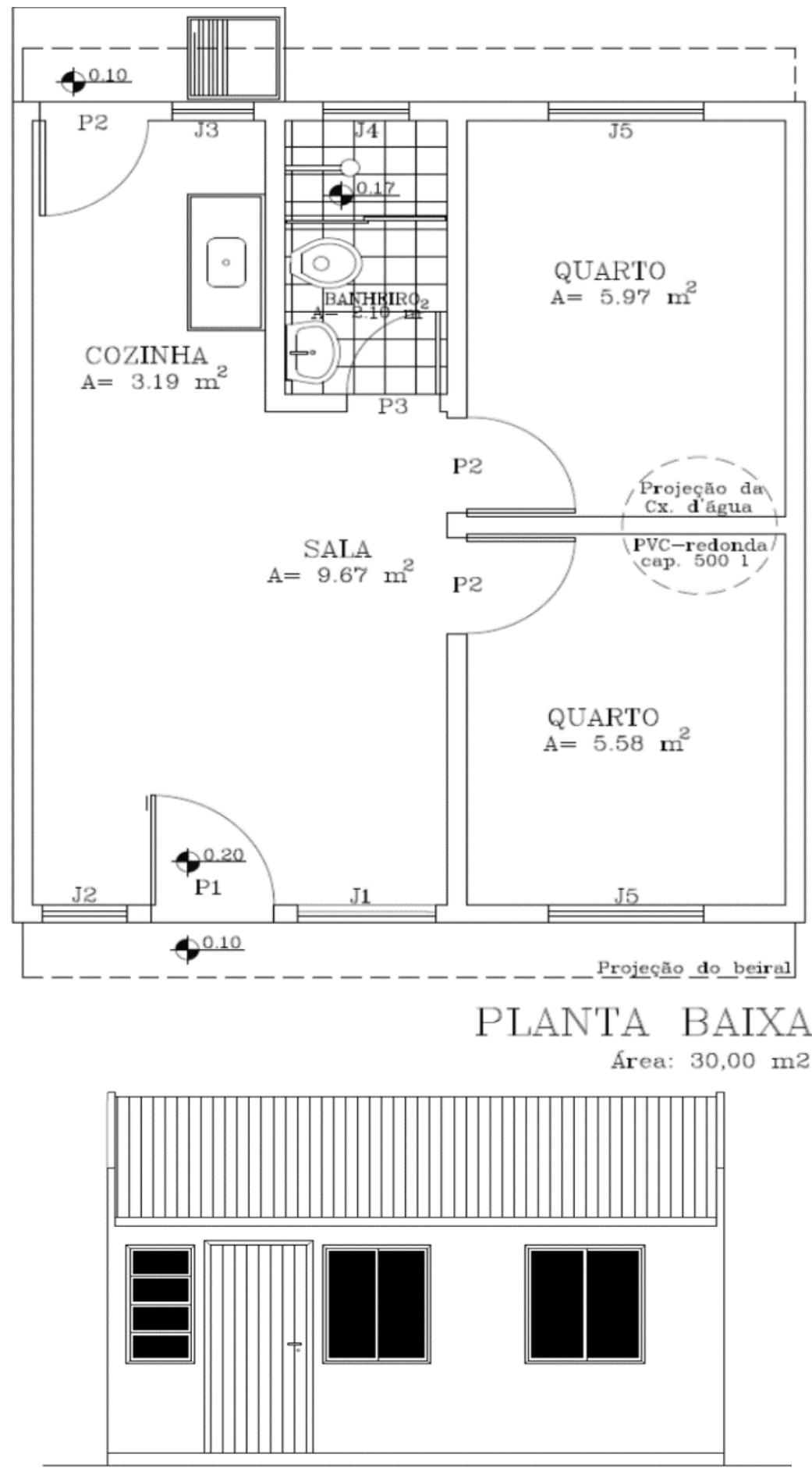

FACHADA FRONTAL

Figura 1: Projeto executivo arquitetônico das residências (fonte: Prefeitura Boa Vista do Buricá/RS)

Ao fazer a visita, o proprietário de cada residência se fez presente e acompanhou o levantamento, apontando o que mais the incomodava e lhe causava desconforto por manifestações patológicas evidentes. 

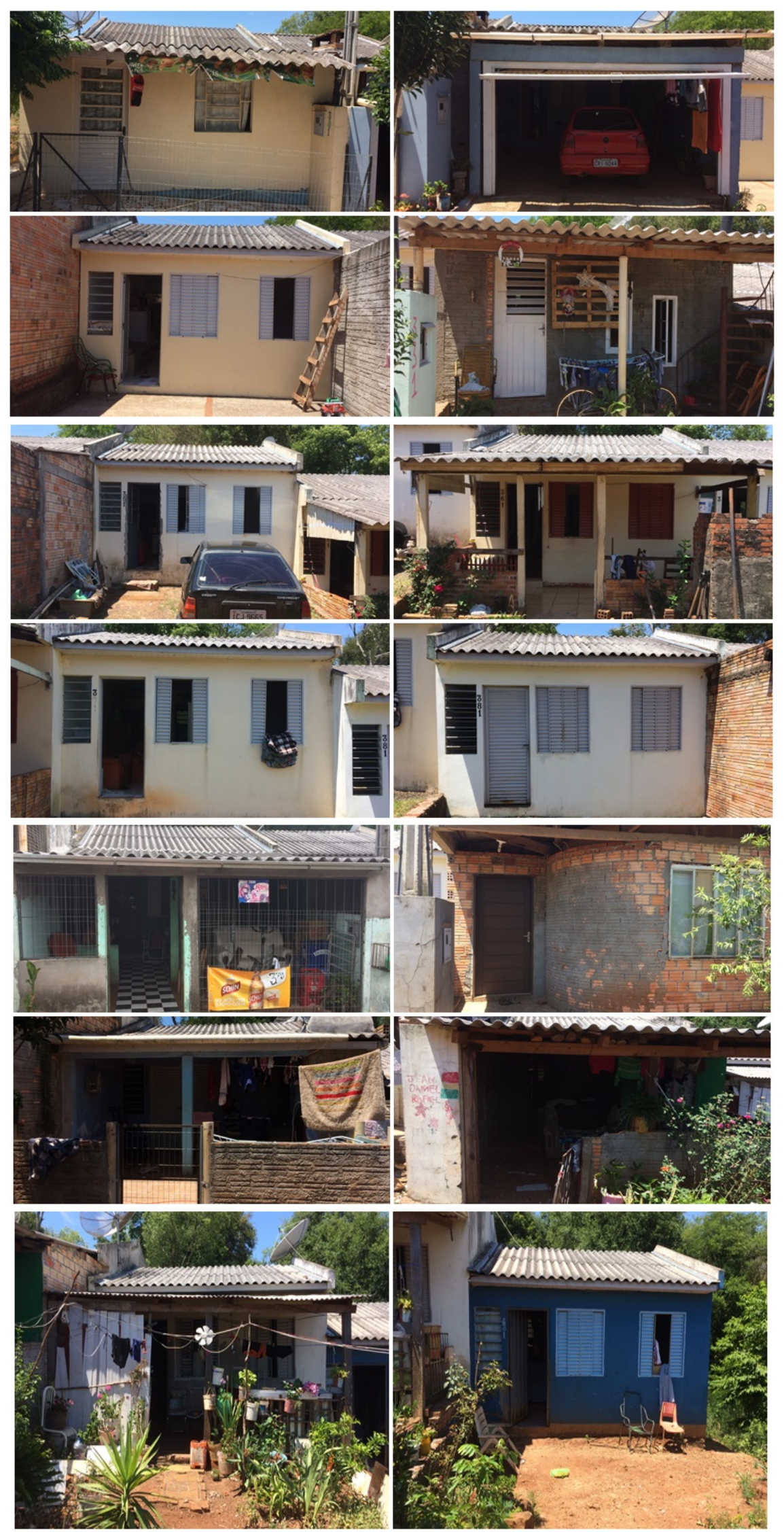

Figura 2: Situação atual das residências de habitação de interesse social 
Ao analisar o memorial descritivo de projeto, observou-se a indicação de impermeabilização sobre os elementos de vigas baldrame com a aplicação de emulsão asfáltica, utilizada conforme a recomendação do fabricante. O memorial também destaca o cuidado necessário para evitar o escorrimento do produto nas laterais dos pilares. Salienta-se que esta foi a única indicação sobre o sistema de impermeabilização encontrada em todo o documento.

Picchi (1986) define que a emulsão asfáltica é obtida misturando cimento asfáltico com água, tratando-se de um impermeabilizante com aplicação a frio e consistência flexível. A função é garantida através da película de asfalto depositada. Porém, somente com a emulsão totalmente curada e em camadas necessárias, esta característica é garantida. Segundo o fabricante do impermeabilizante de emulsão asfáltica, o produto dever ser aplicado sobre a superfície limpa, sua diluição é em uma proporção de 1:1 com água, o produto deve ser aplicado em camadas de 4 a 9 demãos dependendo da área que será impermeabilizada, esse processo deve ser feito com uma brocha ou um pincel.

\section{RESULTADOS E DISCUSSÕES}

As manifestações patológicas foram catalogadas em diversas residências, e notou-se a falha quanto à aplicação de sistema de impermeabilização, assim como a execução de detalhes construtivos que auxiliam na prevenção da ação da umidade sobre a construção.

A relação entre as manifestações encontradas e a quantidade de residências com problemas referentes à umidade são mostradas na Figura 3.

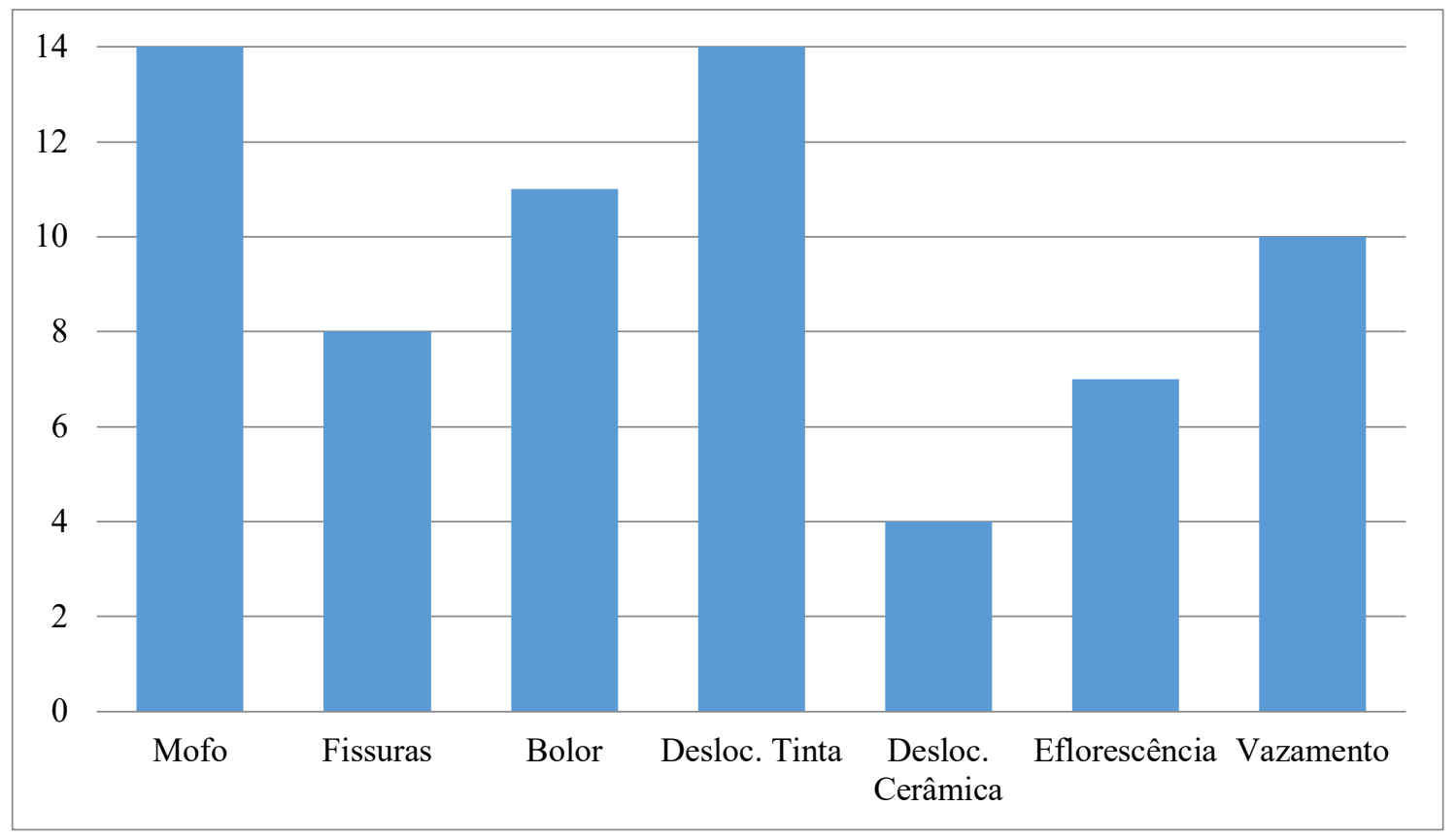

Figura 3: Relação entre manifestações patológicas e número de residências.

É possível observar que todas as residências possuem algum problema quanto a presença de umidade. Todas as construções apresentaram a manifestação de mofo e também de descolamento de pintura.

\subsection{Mofo e bolor}

Segundo Lersch (2003) o mofo e o bolor são fungos que se proliferam em ambientes que contém umidade. Essa manifestação causa alterações estéticas, como formação de manchas escuras (Figura 
4), além da deterioração da construção e o desencadeamento de problemas respiratórios aos usuários (SILVA e JONOV, 2018).
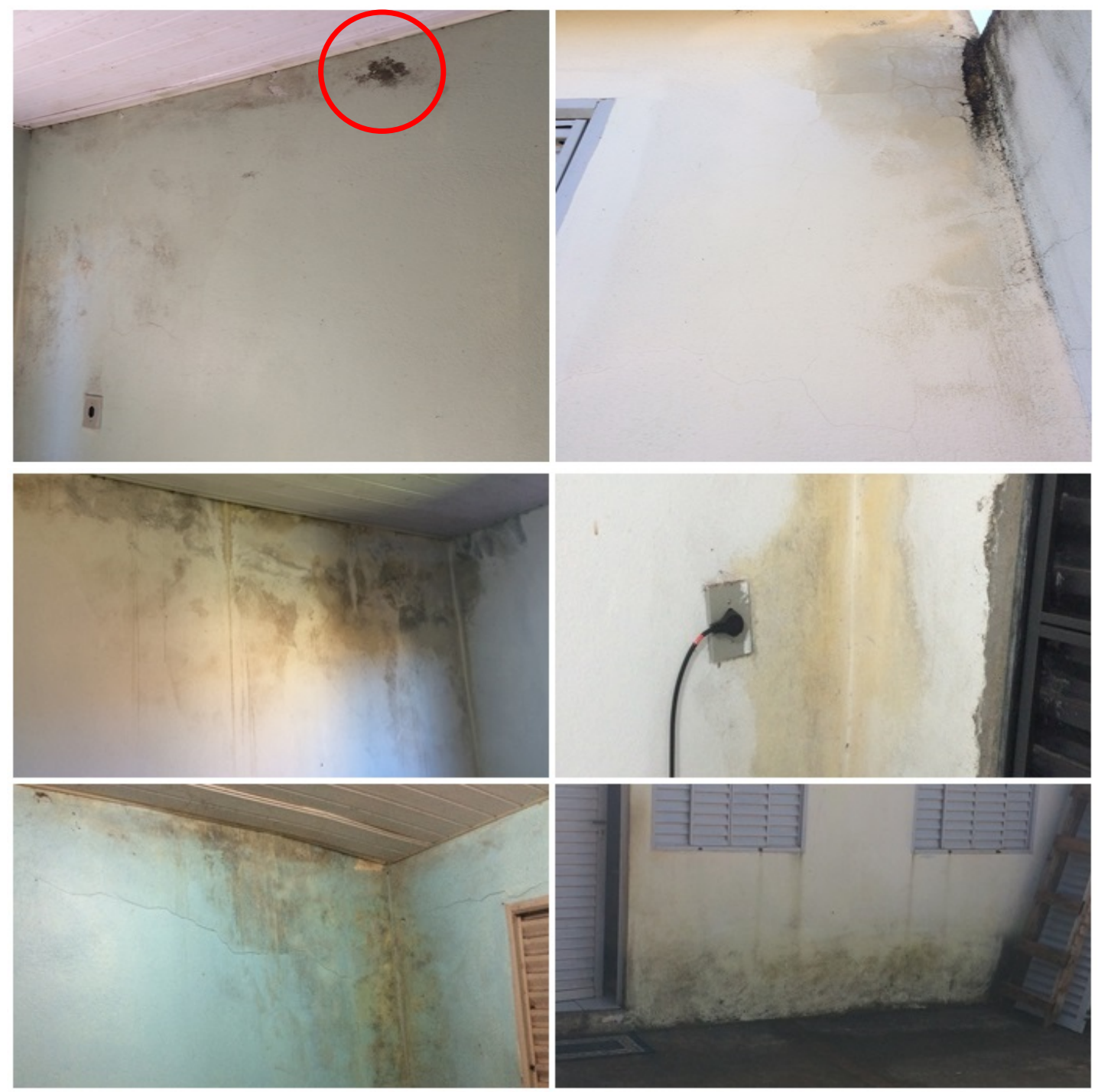

Figura 4: Exemplo de manchas de mofo nas residências

A causa da presença deste tipo de manifestação é dada a partir da combinação entre superfícies expostas à umidade e com pouca luz. Para recuperação é necessário a retirada de pintura e aplicação de produto selador, e após a secagem é possível realizar a pintura novamente. Para situações mais leves, a superfície pode ser limpa com produtos desinfetantes que evitam a proliferação deste tipo de fungos.

Ainda, é importante verificar se a umidade é derivada de vazamentos ou infiltrações diretas, de modo a cessar a fonte inicial que facilita esse tipo de manifestação.

Além disso, nota-se pela última imagem da Figura 4 que a presença de mofo é relacionada pela falha na impermeabilização das vigas baldrames, precisando de tratamento direto. Para esta situação, é indicada a retirada parcial do revestimento, limpeza do substrato e aplicação de sistema impermeabilizante rígido, como argamassa polimérica, argamassa aditivada com impermeabilizante ou cristalizante, em conformidade com as camadas e processos indicados pelo fabricante. 


\subsection{Eflorescências}

As eflorescências (Figura 5) são formações de depósitos salinos na superfície das paredes, migrados do interior da argamassa/alvenaria pela umidade, causando manchas brancas e até mesmo o descolamento da pintura (VERÇOZA, 1991).
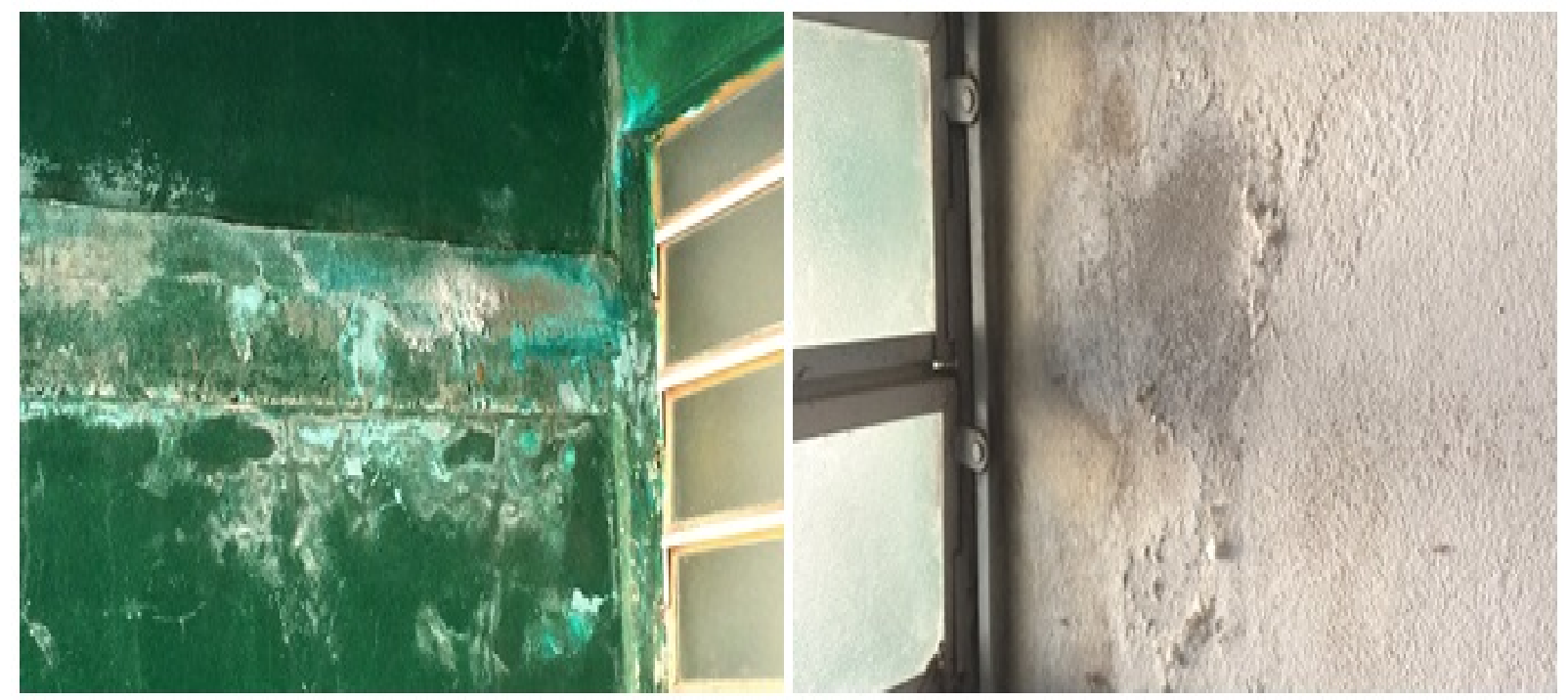

Figura 5: Exemplo de eflorescências nas residências analisadas.

O procedimento adotado para reparar essa manifestação patológica pode partir da limpeza local com auxílio de escova de aço e água em abundância, assim como utilização de produto químico em solução para retirada dos sais cristalizados (UEMOTO, 1988).

\subsection{Descolamento de cerâmicas}

O problema relacionado ao deslocamento de cerâmicas pode ser originado por uma combinação de fatores, entretanto, durante a inspeção presencial notou-se a presença de umidade na região com falha (Figura 6). Essa manifestação foi pouco encontrada devido ao baixo uso revestimento de piso cerâmico, uma vez que foi especificado somente para a área do banheiro pelo projeto original.
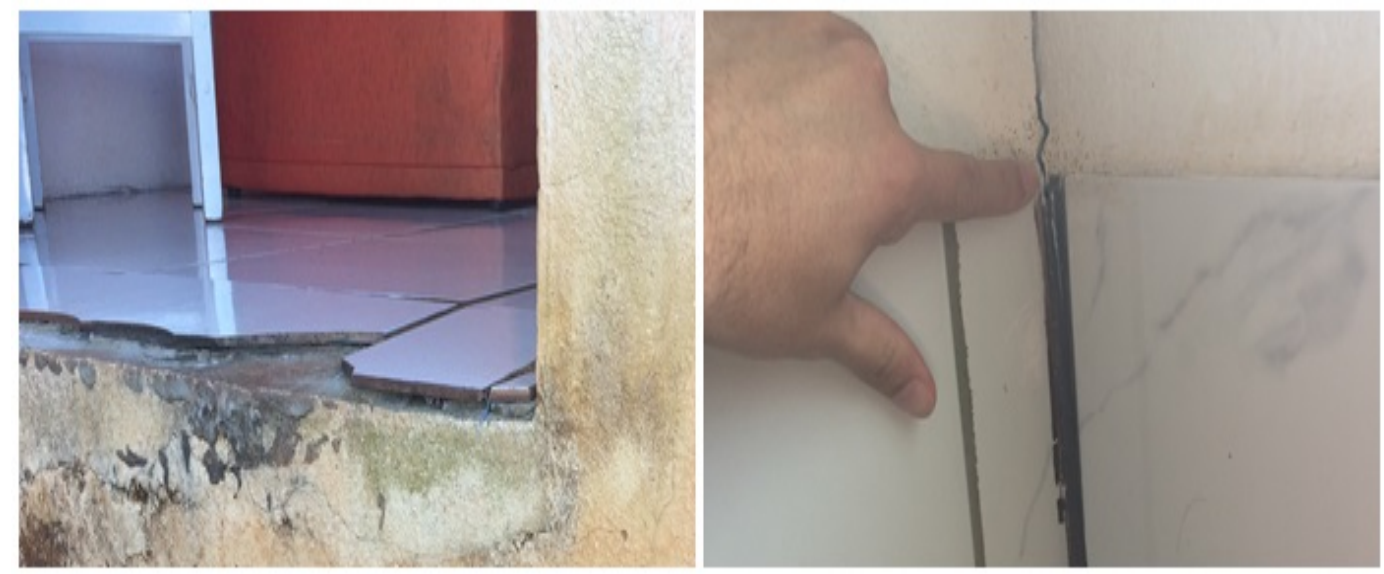

Figura 6: Exemplo de descolamento de cerâmica

Este fenômeno ocorre devido a dilatação higroscópica dos materiais, provocando modificações na estrutural, aumentando o volume e consequentemente, o descolamento na interface argamassa/cerâmica (SILVA e JANOV, 2018). 
Para a solução deste tipo de manifestação é indicado retirar o revestimento e refazer o sistema de modo correto. Caso a área afetada possua alta incidência de umidade, recomenda-se a execução de sistema de impermeabilização, flexível para áreas expostas e rígido para áreas protegidas (ABNT NBR 9574, 2008), como forma de evitar o reaparecimento do problema.

Após o serviço de preparação da base ser feito, o assentamento da cerâmica é realizado com o uso de materiais adequados, preferencialmente com argamassa colante.

\subsection{Descolamento de pintura}

Conforme Hussein (2013), os problemas com o sistema de pintura, como o aparecimento de bolhas, manchas e descascamento (Figura 7), podem surgir por diferentes causas, como a aplicação inadequada da tinta e/ou preparação da base, o tempo de secagem insuficiente de cada camada e a presença de umidade.
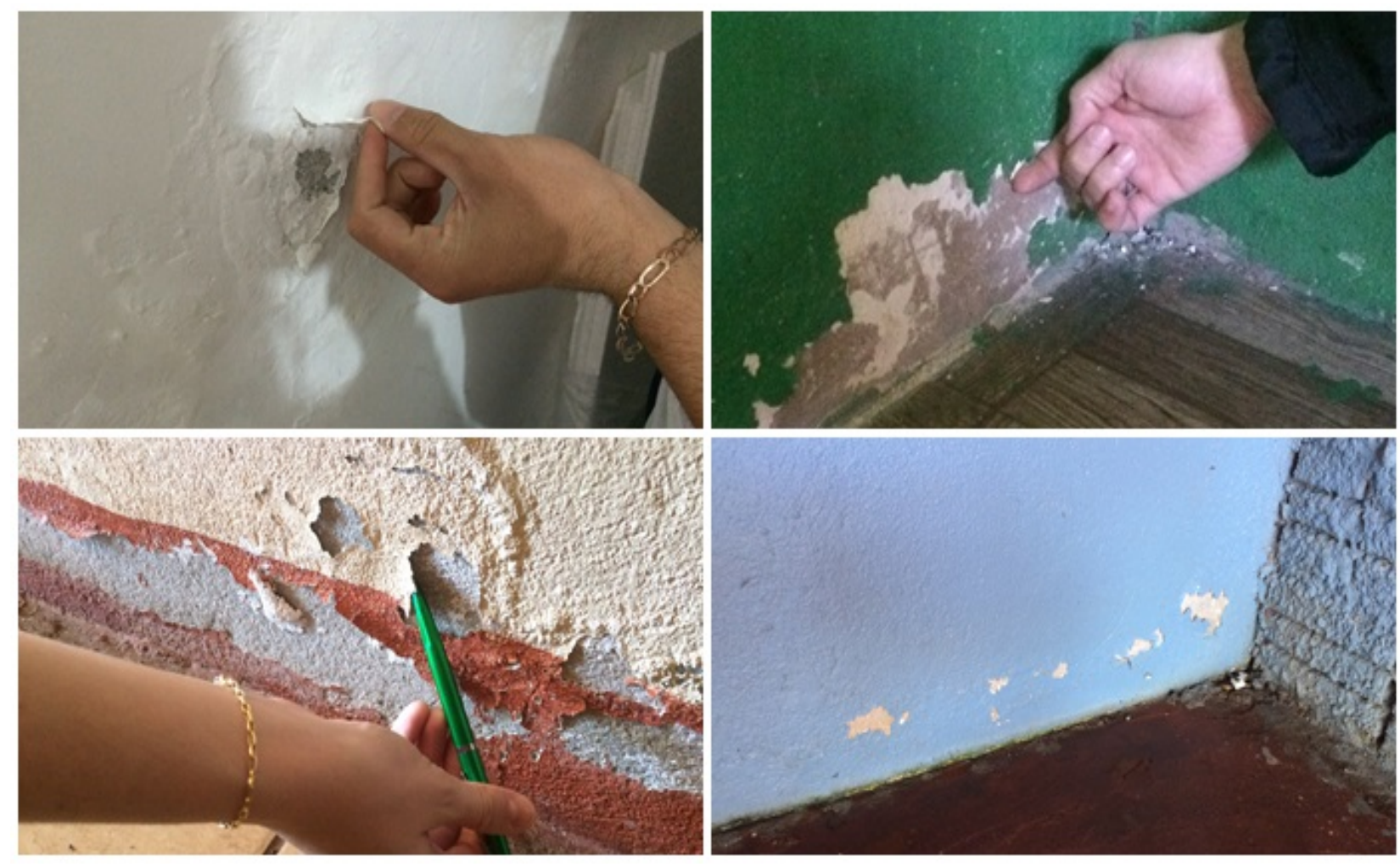

Figura 7: Exemplos de manifestações referentes ao sistema de pintura nas residências.

Os moradores informaram que a pintura é refeita em períodos curtos de tempo, pelo descolamento de tinta ou pela tentativa de reparar as manchas frequentes, entretanto essa solução não resolve o problema, já que a origem da umidade não é tratada.

Sugere-se verificar a fonte de umidade e corrigir através de aplicação de sistema de impermeabilização. Como a maioria das falhas nas pinturas foram encontradas em espaço interno e próxima ao piso, é recomendado a retirada parcial do revestimento, limpeza do substrato, aplicação de impermeabilização rígida, seguindo as recomendações do fabricante. Por fim, a pintura pode ser executada sobre reparo já executado. 


\subsection{Vazamentos e infiltrações}

Em dez residências foram encontrados problemas originados por vazamentos do sistema hidráulico (Figura 8) que resultam em demais manifestações patológicas, como manchas e descolamento da pintura. A norma de desempenho (ABNT NBR 15575, 2021) estabelece que as edificações precisam garantir conforto e segurança aos usuários, a partir de sistemas executados de forma correta.
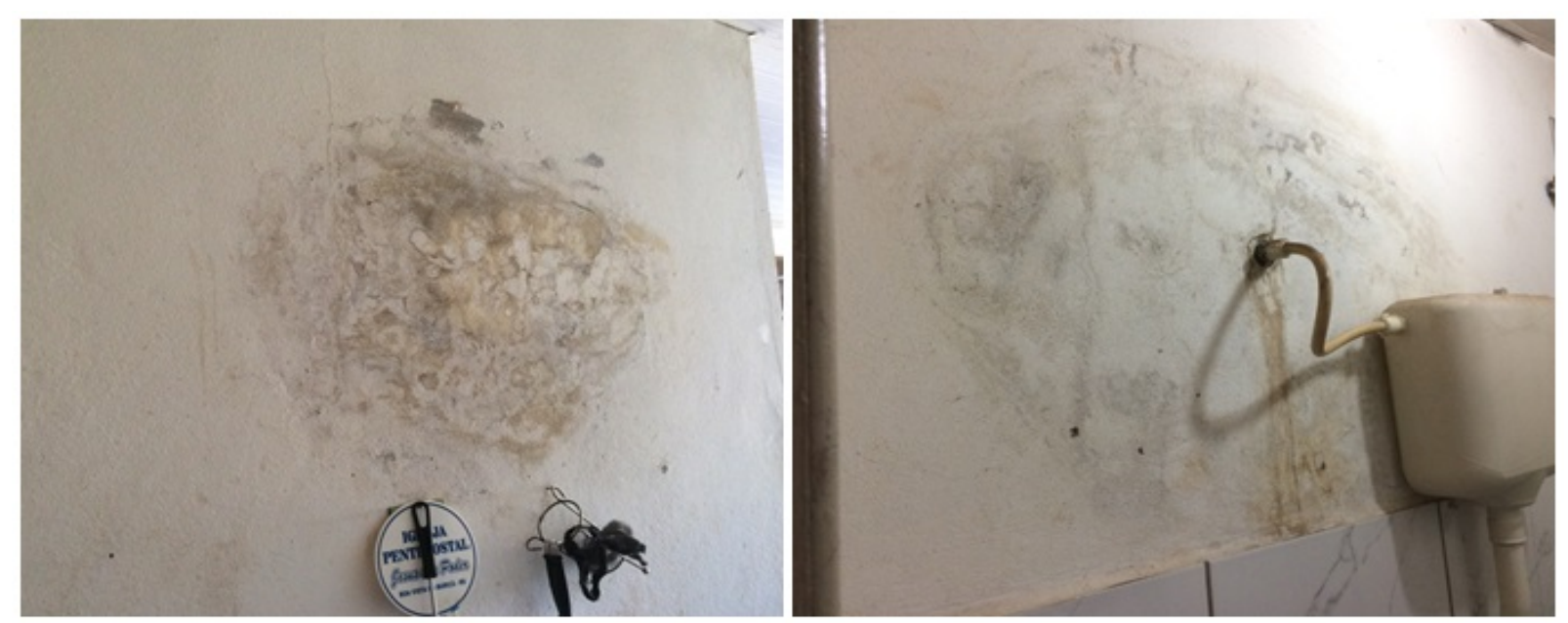

Figura 8: Exemplos de vazamentos de tubulação hidráulica nas residências.

Neste caso em especial, a umidade presente é gerada por um fenômeno atípico, sendo classificada como acidental. Desta forma, é essencial a reparação do problema da fonte de vazamento da tubulação hidráulica, através da

\subsection{Mapeamento de manifestações patológicas}

Como forma de visualizar a ocorrência foi realizado um levantamento das manifestações patológicas presentes em cada cômodo da edificação, como mostra a Figura 9.

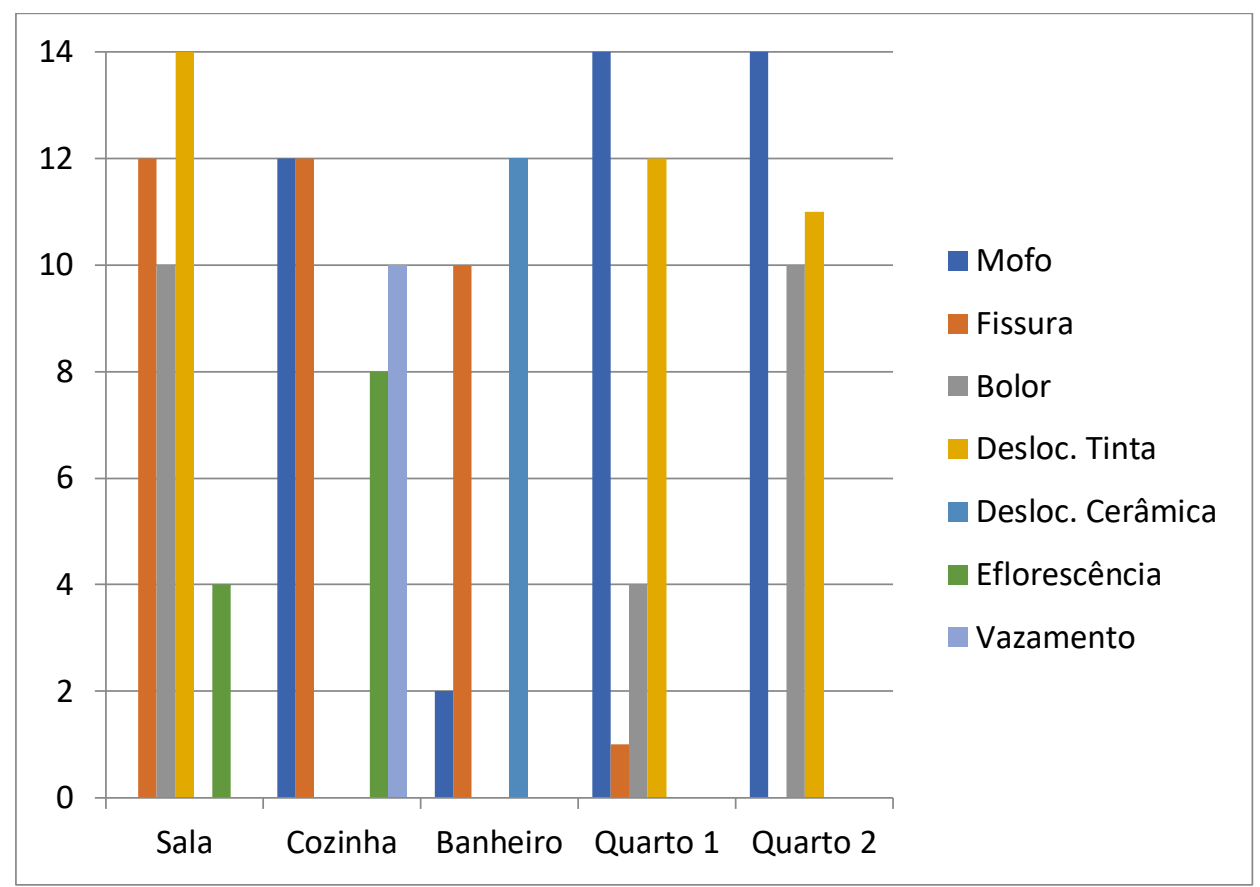

Figura 9: Relação das manifestações patológicas encontradas nos cômodos das residências. 
Em entrevista com os moradores, foi relatado que o maior incômodo é em relação a alta presença de mofo. Como constatado na Figura 9, o mofo está presente em todas as residências em especial nos quartos, com possibilidade de danos à edificação como também à saúde dos usuários. Um desenho esquemático (Figura 10) foi gerado como forma de visualizar melhor as ocorrências de manifestações patológicas, combinado aos dados da Figura 9.

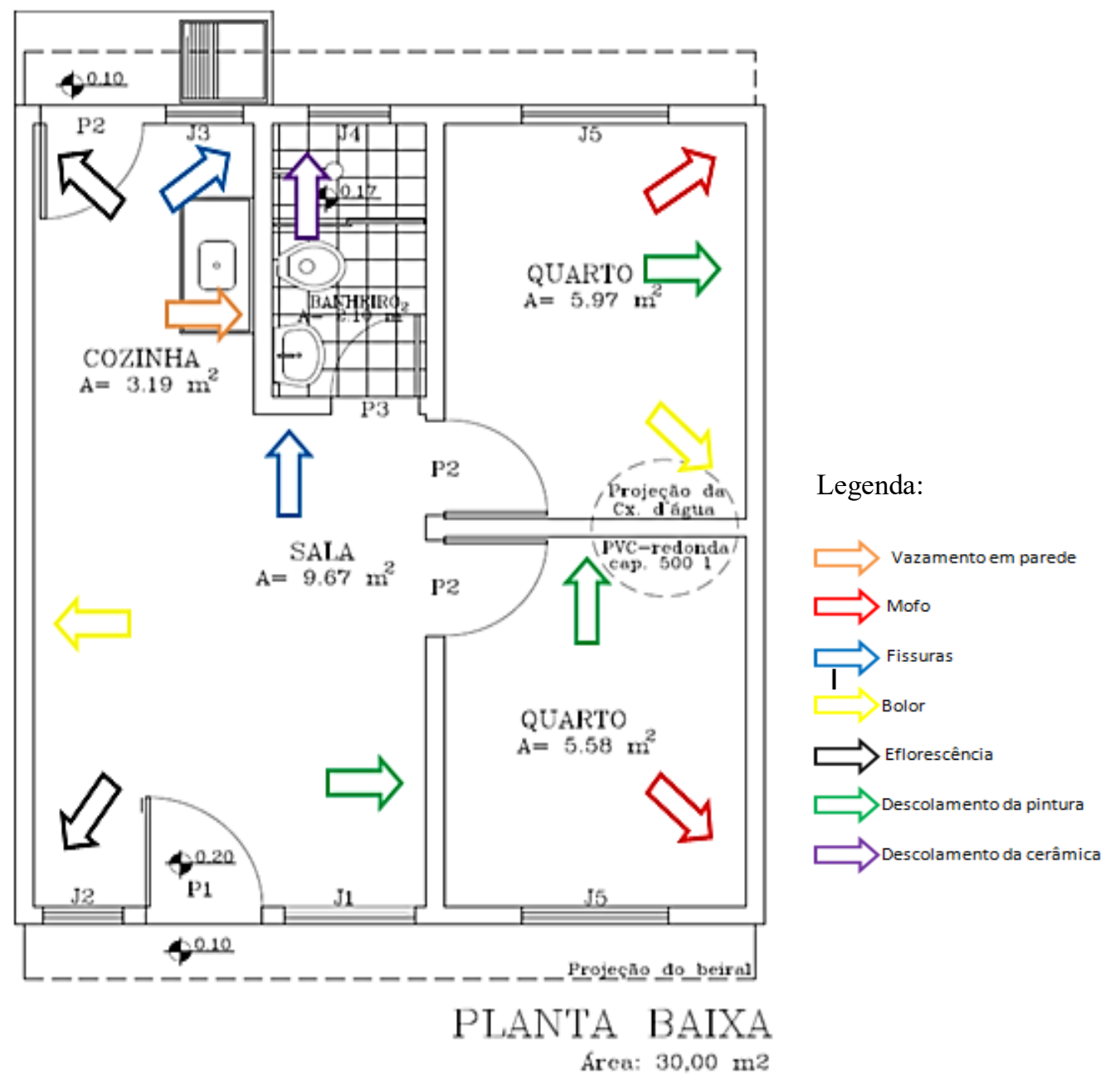

Figura 10: Mapeamento das manifestações patológicas averiguadas.

A partir do levantamento in loco constatou-se que algumas manifestações patológicas ocorridas nos dormitórios podem ser oriundas de vazamentos do reservatório superior, locado sobre a parede divisória (Figura 10). Ainda, pode-se mencionar que manifestações patológicas encontradas na sala de uma residência, pode influenciar no surgimento de manifestações nos quartos da edificação vizinha, uma vez que as casas são geminadas, ou seja, compartilham uma mesma parede.

Por fim, é visível a necessidade de projetos mais elaborados e execução com maior controle para a garantia de entrega de edificações com desempenho mínimo requerido, independentemente do padrão da obra. As residências participantes desse estudo estavam dentro do prazo de garantia da construção, porém inúmeras manifestações patológicas foram relatadas.

O grau elevado dessas ocorrências não só danifica a edificação como um todo ou sistemas isolados, afetando a segurança e durabilidade, como também traz incômodos e possíveis problemas de saúde aos usuários devido ao ambiente com salubridade inadequada. 


\section{CONSIDERAÇÕES FINAIS}

Ao concluir este trabalho, pode-se perceber o alto índice de ocorrência de manifestações patológicas oriundas pela presença de umidade em todos os cômodos das residências verificadas e como a deterioração se torna visível em um curto período de tempo.

Constatou-se que a maioria dos problemas que surgiram nas obras foram por má execução de impermeabilização ou até mesmo inexistência do sistema, reiterando a necessidade de fornecer projetos mais elaborados e possuir plano de execução com inspeção das etapas. Ainda, é importante obedecer às especificações e orientações dos fabricantes de impermeabilizantes, a partir da escolha de sistemas e materiais corretos para tal aplicação.

Os problemas relacionados à umidade estão presentes em todas as fases de uma obra, desde seu projeto até execução e manutenção, sendo assim, a ação preventiva é a melhor solução. A recuperação e manutenção de componentes já degradados gera um custo mais elevado ao proprietário devido aos demais sistemas associados, como por exemplo, a retirada de revestimento. Este trabalho possibilitou o conhecimento de manifestações patológicas e mostrou que é possível diagnosticar a maioria destes problemas nas construções de forma simples e objetiva. A pesquisa revelou ainda que é necessário maior esclarecimento por parte dos profissionais da área de construção civil em relação à importância da de manutenção, assim como se faz necessária a elaboração de projeto de impermeabilização, através da compreensão dos mecanismos de ação da umidade e relação com o sistema.

Por fim, a impermeabilização é uma etapa fundamental em uma obra e não pode ser relegada, devendo ser prevista e pensada em fase de projeto, por um profissional com conhecimento técnico para indiciar o melhor produto, executar corretamente e acompanhar/supervisionar o serviço. Caso não ocorra desta maneira, torna-se mais oneroso executar a impermeabilização e possíveis reparos que irão se fazer necessários, além de trazer transtorno e incômodo aos usuários da edificação.

\section{REFERÊNCIAS}

Associação Brasileira de Normas Técnicas. (2008). NBR 9574 - Execução de impermeabilização. Rio de Janeiro.

Associação Brasileira de Normas Técnicas (2010). NBR 9575 - Impermeabilização: seleção e projeto. Rio de Janeiro.

Associação Brasileira de Normas Técnicas (2021). NBR 15575 - Desempenho de Edificações habitacionais, Rio de Janeiro.

BRITO, J. N. de S.; FORMOSO, C. T.; ECHEVESTE, M. E. S. (2011). Análise de dados de reclamações em empreendimentos habitacionais de interesse social: estudo no Programa de Arrendamento Residencial. Ambiente Construído, Porto Alegre, v. 11, n. 4, p. 151-166.

Castro, M. D. e Martins, R. M. (2014) "Análise e soluções terapêuticas das manifestações patológicas de infiltração de um edifício de mais de 20 anos - Estudo de caso", Trabalho de Conclusão de Curso - Universidade Tecnológica Federal do Paraná, Pato Branco.

MAGALHÃES, R. B; ASSUNÇÃO, R. F; SILVA, L. S; FERREIRA, M. S; ASSUNÇÃO, W. R. (2019). "Estudo de caso de patologias causadas pela umidade face a inexistência de implantação do sistema de impermeabilização nas garagens do $1^{\circ}$ e $2^{\circ}$ subsolo de um edifício residencial 
multifamiliar de múltiplos pavimentos em Belém/PA”. RCT - Revista de Ciência e Tecnologia. v.5, n. 9. p.18.

HUSSEIN, J. S. M. (2013). "Levantamento de patologias causadas por infiltrações devido à falha ou ausência de impermeabilização em construções residenciais na cidade de Campo Mourão/PR". Trabalho de Conclusão de Curso - Engenharia Civil, Universidade Tecnológica Federal do Paraná, Campo Mourão. p. 54.

Lersch, I. M. (2003) "Contribuição para a identificação dos principais fatores de degradação em edificações do patrimônio cultural de Porto Alegre", Dissertação de Mestrado em Engenharia Civil - Universidade Federal do Rio Grande do Sul, Porto Alegre.

PICCHI, F. A. (1986). impermeabilização de coberturas. São Paulo: Pini.

PIEPER, R. (1992). Só se nota a impermeabilização quando ela não existe. Revista Impermeabilizar, São Paulo, n. 43, p. 6.

RIGHI, G. V. (2009), "Estudo dos Sistemas de Impermeabilização: Patologias, Prevenções e Correções - Análise de Casos”. Dissertação de Mestrado - Universidade Federal de Santa Catarina, Santa Maria. p. 94.

RIPPER, T; SOUZA, V. C.M. (1998). "Patologia, recuperação e reforço de estruturas de concreto." São Paulo, Pini.

SILVA A.P, JONOV C.M.P. (2018). Curso de especialização em construção civil. Departamento de engenharia de materiais e construção. Minas Gerais, Brasil. (Notas de Aula)

SOUZA, M. F. (2008) "Patologias ocasionadas pela umidade nas edificações". Monografia (Especialização em Construção Civil) - Universidade Federal de Minas Gerais, Belo Horizonte.

SUPLICY, G.F.S. (2012). “Patologias ocasionadas pela umidade nas edificações”. Trabalho de conclusão de curso apresentado ao Programa de Pós-Graduação Lato Sensu da Escola de Engenharia da Universidade Presbiteriana Mackenzie. São Paulo, SP.

UEMOTO, K. L. (1988), "Patologia: Danos causados por eflorescência. Tecnologia de Edificações”. Pini, IPT - Instituto de Pesquisas Tecnológicas do Estado de São Paulo, Coletânea de trabalhos da Div. de Edificações do IPT. 1988. p.561- 64.

VERÇOZA, E. J. (1991), “Patologia das edificações”. Porto Alegre: Editora Sagra.

WALDHELM, C. (2013), "Manifestações patológicas em unidades habitacionais de baixo padrão do jardim Colúmbia em Londrina-PR”. Dissertação de Mestrado. Engenharia das Edificações e Saneamento, do Centro de Tecnologias e Urbanismo da Universidade Estadual de Londrina - UEL, Londrina - PR.

YAZIGI, W. (2009) “A técnica de edificar”. 10. Ed. Revisada e atualizada. São Paulo: Pini, : Sinduscon. 